\title{
Identifying the Drivers of Food Security Based on Perception among Households in South Western Nigeria
}

\author{
Wasiu Olayinka FAWOLE \\ Department of Agricultural Economics, Faculty of Agriculture, Akdeniz University, Antalya, Turkey \\ Burhan ÖZKAN \\ Department of Agricultural Economics, Faculty of Agriculture, Akdeniz University, Antalya, Turkey
}

\begin{abstract}
Food insecurity has been considered lately as one of the developmental challenges facing developing nations particularly the sub-Saharan Africa that if not curtailed may have embarrassing consequences not only to the affected area but to humanity in general due to instability that may occur. This study aimed to identify those factors that influence food security and how they did to guide the relevant stakeholders in the design and implementation of food programmes. The study assessed food security of the households based on perception of heads/appointed representatives and logistic regression model to identify its drivers in respective households. The findings of the study revealed that majority of households investigated (60.2 percent) showed varying degrees of food insecurity and hunger while those living with moderate hunger were leading by 31.6 percent. Furthermore, logistic regression analysis results showed that eight of the ten explanatory variables such as income, access to credit and public health facilities among others as specified in the model significantly influenced the food security of the sampled households.
\end{abstract}

Keywords: identifying, drivers of food security, perception, households, South Western Nigeria

\section{Introduction}

Food security has been variously defined by various studies and stakeholders alike the latest of which was defined as "a situation that exists when all people, at all times, have physical, social and economic access to sufficient, safe and nutritious food that meets their dietary needs and food preferences for an active and healthy life" (FAO 2002). Also, FAO (2008) categorized food security into four dimensions; availability, accessibility, utilization and sustainability. Each of these dimensions are independent of each other suggesting that achievement of one does not guarantee the achievement another but the achievement of all dimensions are required to attain a state of food security within a population group. However, food insecurity in recent times has been identified as one of the key developmental challenges bedeviling the developing nations particularly the sub-Sahara African countries which could be attributed to many factors some of which the study is trying to examine using south western Nigeria as a reference group and taking into consideration the peculiarities of the affected population. According to the chairperson of World Food Summit held in 2002 and quote "...together with terrorism, hunger is one of the greatest problems the international community is facing...." (Clover 2003). Corroborating this assertion, James Morris, the then executive director of World Food Programme (WFP) in his address to the UN Security Council in December 2002 about Africa's food crisis and equally asserted that in addition to the problems of AIDS/HIV faced by people is another danger posed by food insecurity and hunger where about 38 million people in Africa alone faced imminent threat to their peace, security and stability which has since surged (WFP 2002). According to the latest reports published by the Food and Agricultural Organization (FAO) of the United Nations, food insecurity in the world had risen from 777 million in 2015 to 815 million in 2016 (FAO, 2017).

It is pertinent to note that every food programme requires the full assessment of the prevailing food insecurity among the target vulnerable group before meaningful interventions could take place. For example, food security can be achieved at national level by either self-production or sufficient import in case of lack of resources for self-production like land, climate and other environmental factors that may prevent growing of food crops and rearing of animals for animal protein while it 
can also be achieved by either self-production on family farms or purchase from the market (Fawole 2017). Several studies and investigations have been carried out in respect of determinants of food security in terms of socioeconomic and political characteristics with some coming up with several factors that were seen to influence the food security of groups of people. In the case of Nigeria, declining food production occasioned by neglect of agriculture in the face of growing population has grossly affected the fortunes of food security at national level in the country as a whole with spiral effects on the households who were always the most hit of the effects of food insecurity being the consuming units and are vulnerable to food shocks due to socioeconomic imbalances. For instance, the Nigerian population annual growth rate is estimated as 3.5 percent with accompanying 2.7 percent growth rate or less in agriculture which is largely insufficient to meet food needs of the entire population (NBS 2017).

This study became necessary in view of the fact that most food intervention programmes have not yielded the desired results in most African countries including Nigeria because they have failed to study what drive the food security among different population groups but have majorly relied on templates from other climes with different scenarios. In some cases, most of the implementing partners have been using what obtained in other regions to tackle the problem of food insecurity in Nigeria which has not been working at desired level. For instance, food programmes in the north eastern parts of the country where there have been humanitarian crises triggered by boko haram insurgency have exposed these lapses and confirmed that indeed majority of the implementing partners from international NGOs to UN agencies lacked clear knowledge and information on what drive the food security status of people particularly the vulnerable groups in a country as big as Nigeria with diverse sociopolitical and economic characteristics based on their own convictions and perceptions thus making it difficult to design appropriate food programmes of intervention.

\section{Material and methods}

This study was conducted in south western Nigeria by sampling 161 households using multistage random sampling technique. Primary data collected with the aid of structured questionnaires were used for this study. South West Nigeria was selected based on its strategic importance to food production in Nigeria and at a time all talks on food insecurity in Nigeria have been centered on North East due to insurgency problems there. Furthermore, food security status of the sampled households in the study area were computed based on perception of heads or other appointed representatives on prevailing food security situation in their respective households. This method is innovative in assessing food security of the households to avoid the criticisms based on shortcomings that have always associated with the traditional food indicators that have been used for the same purpose by different authors using various indicators.

\section{Food security based on perception of household heads/appointed representatives}

In assessing food security of the households based on this technique, the following questions were asked from the representatives of the households who were heads or designated individuals familiar with the food supplies and consumption in the households in each case and the responses were recorded and analyzed as follows;

\section{How best can you describe the food security situation in this household based on your perception?}

$$
\text { Food secure, FS }
$$

(ii.) Food insecure (without hunger), FIWH

(iii.) Food insecure (with moderate hunger), FIMH

(iv.) Food insecure (with severe hunger), FISH

\section{Factors affecting food security in the study area}

After getting the food security situation among households as described above, the drivers of food security among households were examined by using binary logistic regression model as specified subsequently. For the purpose of analysis, the dependent variable was household food security based on perception of household heads or other appointed representatives on food security situation in their respective households. In doing this, households who were food secure were marked 1 while those who showed varying degrees of food insecurity like food insecurity without hunger (FIWH), food insecurity with moderate hunger (FIMH) and food insecurity with severe hunger (FISH) were categorized as 0 for the sake of binary logistic regression analysis. This study followed the works of Gujarati and Porter (2009) and Abbas et al (2017). 


\section{Specification of the logistic regression model}

$\mathrm{L}_{i}=\ln \left(\frac{\mathrm{P}_{i}}{1-\mathrm{P}_{i}}\right)=\mathrm{Z}_{i}$

From the general model as specified in (1) above,

$Z_{i}=\beta_{0}+\beta_{i} X_{i}+\mu_{i}$

Where $i=1,2,3 \ldots 10$. The equation (1) above can thus be rewritten as;

$\mathrm{L}_{i}=\ln \left(\frac{\mathrm{p}_{i}}{1-\mathrm{P}_{i}}\right)=\beta_{0}+\beta_{\mathrm{i}} \mathrm{X}_{\mathrm{i}}+\mu_{\mathrm{i}}$

(Gujarati and Porter 2009 and Abbas et al 2017)

Dependent variable $=$ food security $($ food secure $=1$, food insecure $=0$ )

$X_{i}=$ explanatory variables as stated below;

Access to credit facilities (access $=1$, no access $=0$ ), access to public health facilities (access $=1$, no access $=0$ ), coping strategies (number of coping strategies used by household; $0-9$ ), gender status of the household head (Male $=1$, female $=0$ ), age of the household head (in years), marital status of the household head (married $=1$, otherwise $=0$ ), major occupation of the household head (farming $=1$, non-farming $=0$ ), non-food expenditure (in naira), household total monthly income (in naira), state of location of the household (Osun $=1$, Oyo $=0$ ).

\section{Results and Discussions}

\section{Results}

The major findings of the study revealed that majority of the households investigated showed varying degrees of food insecurity and hunger in some cases. However, 39.8 percent of the households were food secure based on perception of the household heads or other appointed representatives who answered questions on prevailing food security situation of the households in the study area. Also, in terms of what drive the food security among households in the study area, eight of the ten explanatory variables specified in the logistic regression model significantly influenced the food security of the households.

\section{Discussions}

The results of the analysis of food security status of households in the study area as shown on Table 1 reveal that food insecurity in the study area is not only high but approaching a dangerous dimension considering the percentage of households that still live with varying degrees of hunger despite previous interventions aimed at halting the trend among the vulnerable population. The implication of these findings as shown on Table 1 is that based on the perception of the household heads and other appointed representatives of the households, majority of the households agree that they are consuming less than required quantity and quality of their preferred food items necessary for their active and healthy living and as such will require external interventions that could ensure provision of foods for immediate consumption or actions that could boost their income generation through sustainable livelihoods that would enable them to acquire their preferred foods for active and healthy living as recommended by United Nations.

Table 1: Classification of households into food security statuses

\begin{tabular}{lll}
\hline Food security status & Number of households & Percentage \\
\hline FS & 64 & 39.8 \\
FIWH & 43 & 26.7 \\
FIMH & 51 & 31.6 \\
FISH & 3 & 1.9 \\
\hline Total & 161 & 100 \\
\hline
\end{tabular}


Field survey, 2016; FS = Food secure, FIWH = Food insecure without hunger, FIMH = Food insecure with moderate hunger, FISH = Food insecure with severe hunger

Furthermore, this study as earlier hinted sought to identify those factors that influenced the food security situation of the households and these findings are as shown on Table 2 subsequently. Also, the respective influences of the specified explanatory variables on the food security status of households are as highlighted shortly;

\section{Accessibility to credit facilities by household head}

The slope of coefficient of access to credit facilities by household head is 1.475 with positive sign and significant $(p<0.1)$ suggesting that having access to credit facilities by household head increases the weighted log of odds in favour of food security in the household by 1.475. Again, based on the odds ratio as depicted on Table 2 subsequently, the results implied that when a household head had access to credit facilities, the odds of being food secure is 4.37 times more than when otherwise. In other words, when a household head had access to credit facilities, the probability of being food secure is 0.29 (29 percent) more than when otherwise when other factors are held constant. These findings are consistent with findings of Amaza et al (2008), Muche et al (2014) and Arene and Anyaeji (2010) but in contrast with those of Babatunde et al (2007a) and Babatunde et al (2007b).

\section{Accessibility to public health facilities}

The slope of coefficient of accessibility to public health facilities by household members is 1.311 with positive sign and significant $(p<0.05)$ suggesting that having access to public health facilities increases the weighted log of odds in favour of food security in the household by 1.311. Again, based on the odds ratio as depicted on Table 2 subsequently, the results implied that when a household had access to public healthcare facilities, the odds of being food secure is 3.71 times more than when the situation is otherwise. In other words, when the household had access to public healthcare facilities, the probability of being food secure is 0.19 (19 percent) more than when the situation is contrary. These findings are well in line with a priori expectation especially considering the utilization dimension of food security but in contrast with the findings of Obayelu (2012) that reported contrary.

\section{Coping strategies utilized by households during food shortages}

The coping strategies $(0-9)$ employed by households during food shortage gave a slope of coefficient of -1.312 , a negative sign and highly significant $(p<0.01)$ suggesting that with every one-unit increase in the number of coping strategies adopted by household, the weighted log of odds in favour of food security decreases by 1.312. Again, based on the odds ratio as depicted on Table 2 subsequently, the results implied that when the number of adopted coping strategies increased by 1 , the odds of being food secure decreased by a factor of 0.27 . In other words, when the number of adopted coping strategies by household during food shortage increased by one-unit, the probability of being food secure decreased by 0.20 (20 percent) when other factors are held constant. These findings are in line with a priori expectation which stated that food security level decreases with increasing number of adopted coping strategies employed by household just as a household that is completely food secure does not use any coping strategy due to food sufficiency being experienced in such household. These results are in congruent with Okwoche and Benjamin (2012).

\section{Age of the household head}

The slope of coefficient of age household head is 0.063 , with a positive sign and significant $(p<0.05)$ suggesting that for every one-year increase in the age of household head, the weighted log of odds in favour of food security increases by 0.063. Again, based on the odds ratio as depicted on Table 2 subsequently, the results implied that when the age of the household head increases by a year, the odds of being food secure also increases by a factor of 1.06 (107 percent). In other word, when the age of a household head increases by a year, the probability of being food secure increases by 0.0096 ( 0.1 percent) when other factors are held constant. These findings are in line with a priori expectation that household headed by old person tends to show higher degree of food security because they have among other things relatively more years of working experience especially those who are working with government and other paid jobs and this in most cases translates to more income accruable to the household on one hand and food security on the other hand. These findings are in congruent with those of lorlamen et al (2013), Obayelu (2012) and Mitiku et al (2012) which reported similar findings but however in contrast with Babatunde et al (2007a) and Babatunde et al (2007b) that reported contrary findings. 


\section{Marital status of the household head}

The slope of coefficient of marital status of household head is -3.643 , with a negative sign and highly significant $(p<0.01)$ suggesting that with a household being headed by a married person, the weighted log of odds in favour of food security decreases by 3.643. Again, based on the odds ratio as depicted on Table 2, the results implied that when a household is headed by a married person, the odds of being food secure 0.03 ( 3 percent) lesser than when otherwise. In other word, when a household is headed by a married person, the probability of being food secured is 0.72 (72 percent) lesser than when otherwise when other factors are held constant. These results are in congruent with the findings of Obayelu (2012) which reported that household headed by married persons showed less food security than when the situation is contrary which might have been as a result of fewer people or in some cases only one person in a household when the head is not married.

\section{Major occupation of the household head}

The slope of coefficient of major occupation of household head is -1.051 . The negative sign is significant $(p<0.1)$ suggesting that having farming as major occupation of household head decreases the weighted log of odds in favour of food security in the household by 1.051. Again, based on the odds ratio as depicted on Table 2 subsequently, the results implied that when the major occupation of a household head is farming, the odds of being food secure is 0.35 times less than when the major occupation of household head is non-farming. In other word, when the major occupation of a household head is farming, the probability of being food secure is 0.16 (16 percent) less than when the major occupation is nonfarming when other factors are held constant. These findings are in agreement with Okwoche and Benjamin (2012) which reported similar findings but however in contrast with the findings of Omotesho et al (2006) and Obayelu (2012) which held that farming as major occupation headed households were more food secure. Households headed by someone with nonfarming as major occupation could possibly have shown more food security than ones headed by someone with farming as major occupation due to disparity in income as those with non-farming major occupation might have had access to different varieties of food items for his households unlike the one headed by farmer who relied solely on seasonal and unsustainable food supplies from family farm.

\section{Total monthly income of household head (Naira)}

The slope of coefficient of total monthly income of the household head is $5.5 \mathrm{e}-06$, with a positive sign and significant $(p<$ 0.05 ) suggesting that with every one-naira increase in total household monthly income, the weighted log of odds in favour of food security increases by 5.5e-06. Again, based on the odds ratio as depicted on Table 2 subsequently, the results implied that when the total household income increased by 1 naira, the odds of being food secure also increased by a factor of 1 meaning that the household food security and total household income change in the same proportion and positive direction. Similarly, when the income of a household increased by 1 naira, the probability of household being food secure also increased by 0.000085 percent when other factors are held constant. These findings are consistent with those of Mitiku et al (2012) and Arene and Anyaeji (2010) which also reported significant and positive relationship between household income and food security in their respective studies but in contrast with the findings of Kuwenyi et al (2014) and Ndhleve et al (2013) which reported otherwise.

\section{State of location of the household (Osun or Oyo)}

The slope of coefficient of state of location of household is -1.28 , with a negative sign and significant $(p<0.05)$ suggesting that with household located in Osun, the weighted log of odds in favour of food security decreases by 1.28 . This is in contrast to what obtained in food security according based on food expenditure. This is unconnected with lower cost of living in Osun state as compared with what obtained in Oyo state. This is however not the case as seen here with food security based on self-report. Again, based on the odds ratio as depicted on Table 2 subsequently, the results implied that that when a household is located at Osun, the odds of being food secure is 0.278 less than when the household is located in Oyo. In other word, when a household is located in Osun, the probability of being food secure is 0.19 less than when located in Oyo.

Generally, the results showed that all the explanatory variables had marginal effects on the food security status of the households considering their relatively low $p-$ value $(p<0.001)$. The model is considerably fit going by the values of Pseudo $R^{2}$ and percentage of correct predictions (count $R^{2}$ ) of 0.560 and 86.3 respectively as shown on Table 2 . The Hosmer-Lemeshow chi (8) value is 9.81 which showed that the model correctly fits the data. 
Table 2: Results of Logit analysis identifying drivers of food security

\begin{tabular}{|c|c|c|c|c|c|c|}
\hline Variables & Coefficient & SE & $z$ - stat & $p>|z|$ & Odds ratio & ME \\
\hline Constant & 0.2476 & 1.6615 & 0.15 & 0.882 & - & - \\
\hline +Access to credit facilities & $1.4749^{*}$ & 0.8660 & 1.70 & 0.089 & 4.3706 & 0.2850 \\
\hline +Access to public health facilities & $1.3112^{\star *}$ & 0.6202 & 2.11 & 0.035 & 3.7106 & 0.1949 \\
\hline Coping strategies utilized & $-1.3117^{\star \star \star}$ & 0.2162 & -6.07 & 0.000 & 0.2694 & -0.2002 \\
\hline +Gender & 2.2734 & 1.4464 & 1.57 & 0.116 & 9.7123 & 0.1818 \\
\hline Age of the household head & $0.0627^{* *}$ & 0.0309 & 2.03 & 0.042 & 1.0647 & 0.0096 \\
\hline +Marital status of household head & $-3.6433^{\star * \star}$ & 1.3962 & -2.61 & 0.009 & 0.0262 & -0.7195 \\
\hline +Major occupation of H/head & $-1.0505^{*}$ & 0.6298 & -1.67 & 0.095 & 0.3498 & -0.1612 \\
\hline Non-food expenditure shares & 0.00001 & $8 \mathrm{E}-06$ & 1.37 & 0.172 & 1.0000 & 1.7E-06 \\
\hline Total household monthly income & $5.5 \mathrm{E}-06^{* *}$ & $2.8 \mathrm{E}-06$ & 1.97 & 0.049 & 1.0000 & $8.5 \mathrm{E}-07$ \\
\hline +State of location of the household & $-1.2800^{* *}$ & 0.5911 & -2.17 & 0.030 & 0.2780 & -0.1922 \\
\hline Log likelihood & -47.58 & \multicolumn{2}{|c|}{ No of observations } & 161 & Akaike info & 0.728 \\
\hline $\operatorname{LR}_{\text {chi² }}(10)$ & 121.22 & \multicolumn{2}{|c|}{ Mean marginal effects } & 0.188 & Schwarz & 0.938 \\
\hline Hosmer-Lemeshow chi² (8) & 9.81 & \multicolumn{2}{|c|}{ Prob. $>\operatorname{chi}^{2}$ (p-value) } & 0.0000 & & \\
\hline Percentage of correct predictions & 86.3 & \multicolumn{2}{|c|}{ Pseudo $\mathrm{R}^{2}$} & 0.5602 & & \\
\hline
\end{tabular}

Source: Estimates of the Logit analysis results for field survey, 2016; SE: Standard Error; ME: Marginal effects; (+) represents dummy variables (0 or 1); Dependent variable: Food security; ${ }^{* *}$ Significant at $1 \%$ level, ${ }^{*}$ Significant at $10 \%$ level.

\section{Conclusions and recommendations}

From the findings of this study, it can be concluded that food insecurity in the study area is a growing concern as revealed by findings of similar studies conducted previously in the study area. The methodology used was an innovative assessment technique that is gaining ground in the assessment of food security in developing countries going by its relative simplicity particularly in terms of affordability as most developing countries lack accurate and reliable data for assessing food security. In order to overcome the problem of food insecurity and hunger in Nigeria, all hands must be on deck to addressing various factors that significantly affect the food security among households as identified by these findings by taking into consideration how each variable affects food security of the households. As an illustration to guide the stakeholders in foodsub sector, there must be policies and programmes that guarantee economic access to resources of production like credit facilities to enable the households have unhindered access to their preferred foods for their active and healthy living. Also, provision must be made for qualitative healthcare facilities that will be accessible and affordable considering the role it plays in maintaining food security particularly the utilization dimension of it which also requires good sanitation and hygiene. Furthermore, there must be adequate provision for the married and those households with more members to feed on through some social protection programmes as it is done in developed countries which could be in form of creation of employment opportunities for the young members with a view to ensuring additional income to the households to guarantee economic access to food items of their choice. Again, the major occupation of households was seen to influence food security of households negatively with households headed by someone whose major occupation is non-farming showing more food security. What this implies is that there should be policies that will encourage diversification of livelihoods among households particularly farming households whose major source of income is farming which is largely rain-fed in most African countries and mostly at subsistence level thus may not be able to sustain those who depend on it for their source of income and food round the year owing to post-harvest loss due to lack of storage facilities and other factors alike. The income as expected influenced food security of the households positively with food security increasing with income among households which could be sustained by recommendations earlier made with regards to diverse and sustained livelihoods. Finally on the state of location of households either in Osun or Oyo, it is suggested that a comprehensive and holistic assessment of food security is carried out across the geopolitical zones particularly in the whole of south west with a view to compare and contrast the food security across states and come up with policy integration that will enable the states compare notes particularly on agriculture or other income generating activities to enable the most food insecure states 
embrace policies and programmes of most food secure states especially in the area of agricultural policy that deals with food production and distribution systems.

\section{References}

[1] Abbas, T., Ali, G., Adil, S.A., Bashir, M.K., \& Kamran, M.A. (2017). Economic analysis of biogas adoption technology by rural farmers: The case of Faisalabad district in Pakistan. Renewable Energy, 107, 431 - 439.

[2] Amaza, P. S., Adejobi, A. O. and Fregene, T. (2008), "Measurement and determinants of food insecurity in North East Nigeria: Some Empirical Policy Guidelines", Journal of food, Agriculture and Environment. Vol. 6 No. 2, pp. 92-96.

[3] Arene, C.J. and Anyaeji, R.C. (2010), "Determinants of Food Security among Households in Nsukka Metropolis of Enugu State of Nigeria", Pakistan Journal of Social Sciences (PJSS), Vol. 30 No. 1, pp. 9-16.

[4] Babatunde, R. O., Omotesho, O.A. and Sholatan, O. S. (2007a), "Socio-economics Characteristics and Food Security Status of Farming Households in Kwara State, North Central Nigeria", Pakistan Journal of Nutrition, Vol. 6 No. 1, pp. 49-58

[5] Babatunde, R.O., Omotesho, O.A. and Sholotan, O.S. (2007b), "Factors Influencing food security Status of rural farming households in North Central Nigeria, Agricultural Journal, 2 (3), pp. 351-357

[6] Clover, J. (2003), "Food Security in Sub-Saharan Africa", African Security Review, Vol. 12 No. 1, pp. 5-15.

[7] FAO (2002), "The State of Food Security and Nutrition in the World 2017, Rome", Available online at: http://www.fao.org/3/aI7695E.pdf

[8] FAO (2008), "An introduction to basic concepts of food security", EC-FAO Food security Programme, available online at: http://www.foodsec.org/docs/concepts_guide.pdf

[9] FAO (2017), "The State of Food Insecurity in the World 2001, Rome", Available online at: www.fao.org

[10] Fawole, W.O. (2017), "Assessment of food security situation among households in south western Nigeria Post-MDGs era", $\mathrm{PhD}$ Dissertation, Unpublished

[11] Gujarati, D. N. and Porter, D.C. (2009), "Basic Econometrics, $5^{\text {th }}$ edition, McGraw-Hill, New York, 2009

[12] Iorlamen, T.R., Abu, G.A. and Lawal, W.L. (2013), "Comparative Analysis on Socio-economic Factors between Food Secure and Food Insecure Households among Urban Households in Benue State, Nigeria", Journal of Agricultural Science, Vol. 4 No. 2, pp. 63-68.

[13] Kuwenyi, S, Kabuya, F.I and Masuku, M.B. (2014), "Determinants of Rural Households' Food Security in Shiselweni Region, Swaziland: Implications for Agricultural Policy", IOSR Journal of Agriculture and Veterinary Science (IOSR-JAVS). Vol. 7, Issue 11 Ver. III, pp. 44-50.

[14] Mitiku, A., Fufa, B. and Tadese, B. (2012), "Analysis of Factors Determining Households Food Security in Pastoral Area Oromia Region, Moyale District, in Ethiopia", International Journal of Agricultural Science, Research and Technology, Vol. 2, No. 3, pp. 105-110, Available online at: http://journals.iau.ir/article_517520_6a416b6674ddf60742bac6e7f10b6167.pdf.

[15] Muche, M, Endalew, B. and Koricho, T. (2014), "Determinants of Household Food Security among Southwest Ethiopia Rural Households", Food Science and Technology Vol. 2 No. 7, pp. 93-100, available online at: http://www.hrpub.org/download/20150101/FST1-11102511.pdf, doi: 10.13189/fst.2014.020701.

[16] Ndhleve, S., Musemwa, L. and Zhou, L. (2013), "Household food security in a coastal rural community of South Africa: Status, causes and coping strategies", African Journal of Agriculture and Food Security, Vol. 1 No. 1, pp.15-20.

[17] Obayelu, A.E. (2012), "Households' food security status and its determinants in the North-Central Nigeria", Journal of Food Economics, Vol. 9 No. 4, pp. 241-256. Available online at: http://dx.doi.org/10.1080/2164828X.2013.845559 doi: 10.1080/2164828X.2013.845559

[18] Okwoche, V.A. and Benjamin, C.A. (2012), "Analysis of food security situation among Nigerian rural farmers", International Journal of Biological, Biomolecular, Agricultural, Food and Biotechnological Engineering, Vol. 6 No. 12, pp. 1-5

[19] Omotesho, O.A., Adewumi, M.O, Muhammad-Lawal, A. and Ayinde, O.E. (2006), "Determinants of Food Security among the Rural Farming Households in Kwara State, Nigeria", African Journal of General Agriculture, Vol. 2 No.1, pp. 7-15.

[20] World Food Programme, (2002), "World Food Summit", 3 December 2002, available online at: pp. 2 